\title{
Rancang Bangun Prototype Flowmeter Air Digitial Prabayar Pada PDAM Berbasis Online Menggunakan Arduino Uno
}

\author{
Ahmad Zaenudin, Herry Setyawan, Aji Brahma Nugroho \\ Teknik Elektro, Fakultas Teknik, Universitas Muhammadiyah Jember \\ Jalan Karimata No. 49, Jember \\ E-mail: ahmedzaenudin@gmail.com
}

\begin{abstract}
ABSTRAK
Abstrak - Pemerintah daerah memasang meteran air pada rumah rumah warga yang setiap bulannya dilakukan perhitungan mengunakan sistem manual yaitu dengan mendatangkan petugas ke rumah warga untuk mencatat stand meteran air. Dari stand meter tersebut dikalikan harga perkubik volume airnya sesuai dengan kelompok pelanggan. Sehingga banyak kekurangan dari sistem manual tersebut yang merugikan warga diantaranya kesalahan pencatatan meter dan kesalahan dalam perhitungan pemakaian volume air pada konsumen. Stand meter juga tidak sesuai karena mengunakan rata rata pemakaian pelanggan disetiap bulannya. Penelitian saya ini mempunyai tujuan untuk mengurangi dan meminimalisir kesalahan pencatatan stand meter oleh petugas dan juga perhitungan pemakaian dengan membuat meteran air digital prabayar PDAM berbasis online. Terdapat juga back up power supply yaitu generator air untuk charger powerbank, sehingga pada saat listrik padam, meteran air digital prabayar tetap bisa nyala dan mengukur air yang mengalir melalui sensor. Jumlah pemakaian volume air dapat diketahui dengan sensor flowmeter yang mengeluarkan sinyal ke mikrokontroler untuk diproses dan ditampilkan volume air yang dibaca ke LCD. Mikrokontroler juga memproses hasil baca dari sensor flowmeter ini kepada modul wifi ESP8266 yang nantinya akan mengirimkan hasil informasi tersebut untuk di rekam secara berkala dan disimpan di web yang sudah terintegrasi oleh signal yang dikirimkan oleh reciver dari modul wifi yang nantinya hasil rekam informasi tersebut mampu diakses oleh server yang kemudian dapat dibaca oleh masing masing user, hasil pembacaan dapat diakses dimana dan kapan saja yang terkoneksi dengan internet.
\end{abstract}

Kata kunci: Flowmeter, Prabayar, ESP8266, Online, Generator.

\section{ABSTRACT}

\begin{abstract}
The local government installs water meters in residents 'houses which are calculated using a manual system every month, namely by bringing in officers to the residents' houses to record the water meter stands. From the meter stand, the per cubic price of the water volume is multiplied according to the customer group. So that there are many shortcomings of the manual system that are detrimental to residents, including errors in recording meters and errors in calculating water volume usage for consumers. The meter stand is also not suitable because it uses the average customer usage each month. My research has the aim of reducing and minimizing errors in recording stand meters by officers and also calculating usage by making online-based PDAM prepaid digital water meters. There is also a back up power supply, namely a water generator for power bank chargers, so that when the power goes out, the prepaid digital water meter can still be on and measure the water flowing through the sensor. The amount of water volume used can be determined with a flowmeter sensor that issues a signal to the microcontroller for processing and displays the volume of water read on the LCD. The microcontroller also processes the read results from this flowmeter sensor to the ESP8266 wifi module which will send the results of the information to be recorded periodically and stored on the web which has been integrated by the signal sent by the receiver from the wifi module which will then be able to access the recorded information. server which can then be read by each user, the reading results can be accessed anywhere and anytime connected to the internet.
\end{abstract}

Keyword: Flowmeter, Prepaid, ESP8266, Online, Generator. 


\section{PENDAHULUAN}

Pendahuluan Air adalah kebutuhan primer manusia sehari hari. Pemerintah daerah memasang meteran air pada rumah rumah warga yang setiap bulannya dilakukan perhitungan mengunakan sistem manual yaitu dengan mendatangkan petugas ke rumah warga untuk mencatat stand meteran air. Dari stand meter tersebut dikalikan harga perkubik volume airnya sesuai dengan kelompok pelanggan. Sehingga banyak kekurangan dari sistem manual tersebut yang merugikan warga diantaranya kesalahan pencatatan meter dan kesalahan dalam perhitungan pemakaian volume air pada konsumen. Stand meter juga tidak sesuai karena mengunakan rata rata pemakaian pelanggan disetiap bulannya. Berdasarkan latar belakang tersebut, maka saya tertarik membuat penelitian yang berjudul "Rancang Bangun Prototype Flowmeter Air Digital Prabayar Pada PDAM Berbasis Online Mengunakan Arduino Uno [1].

Penelitian saya ini mempunyai tujuan untuk memantau volume penggunaan air PDAM pada pelanggan, dengan menggunakan sensor flowmeter yang diaplikasikan ke dalam meteran air prabayar berbasis online.

\section{KAJIAN PUSTAKA}

Penelitian pengukuran aliran air seperti ini sudah banyak dilakukan sebelumnya. Pada tahun 2009 terdapat penelitian yang terkait dari Fathor Rohman yang berjudul "Prototype Alat Pengukur Kecepatan Aliran dan Debit Air (Flowmeter) dengan Tampilan Digital" pada penelitian tersebut output yang ditampilkan perbandingan debit aliran antara flowmeter manual dan optocoupler. Pada tahun 2014 terdapat penelitian yang terkait juga dari Pradana H.A yang berjudul "Rancang Bangun Aplikasi Monitoring Penggunaan Air PDAM Berbasis Mikrokontroler Arduino Uno" pada penelitian tersebut output yang ditampilkan ada dua yakni nilai debit air dan nilai rupiah dari pemakaian volume air. Dimana volume pemakaian air dan nilai rupiah akan bertambah apabila ada pemakaian air. Kemudian Faisal Rahman dan Kusworo Adi pada tahun 2015 melakukan penelitian yang berjudul "Rancang Bangun Sistem Penghitung Pengunaan Air Prabayar Menggunakan Mikrokontroler PIC16F877A" pada penelitian tersebut hasil output yang ditampilkan korelasi penghitung debit air yang ada dengan flowmeter dan pengujian tarif didapat nilai error yang kecil [2][3][4].

Penelitian yang akan saya buat memiliki prinsip kerja yang sama dengan penelitian sebelumnya. Output Penelitian diatas hanya untuk memantau pemakaian air. Perbedaan terhadap penelitian yang akan saya buat ini lebih kompleks karena mengunakan sistem yang pintar yaitu prabayar untuk mengontrol pemakaian volume air. Alat ini dilengkapi dengan generator air untuk backup charger powerbank apabila terjadi listrik padam, sehingga meteran air tetep nyala dan mengukur aliran air yang mengalir melalui sensor flowmeter. Alat ini terdapat buzzer untuk alarm peringatan ketika kuota volume air akan segera habis dan juga alat ini berbasis online untuk mempermudah konsumen dan petugas PDAM untuk memantau pemakaian volume air dan kuota sisa debit air.

\subsection{Sistem Prabayar}

Sistem prabayar biasa disebut dengan sistem pintar. Dimana konsumen bias mengendalikan dan memantau pemakaiannya sendiri. Pelanggan pascabayar biasanya terlebih dahulu menggunakan volume air yang dipakai oleh konsumen, kemudian membayar rekening tagihan meteran air setiap awal bulan sesuai dengan pemakaian volume air yang sudah digunakan. Sedangkan system prabayar adalah system yang mengharuskan konsumen membayar dulu sebelum konsumen memakai air [4].

\subsection{Modul ESP8266}

ESP8266 adalah chip Wi-Fi yang bisa dikatakan murah tetapi mempunyai kemampuan mengatur $T C P / I P$ dan MCU (unit mikrokontroler) yang diproduksi oleh produsen China yang berbasis di Shanghai, Espressif Systems. Chip ESP pertama kali mendapat perhatian para pembuat Barat pada Agustus 2014 dengan modul ESP-01, dibuat oleh produsen pihak ketiga, Ai-Thinker. Modul kecil ini memungkinkan mikrokontroler untuk terhubung ke jaringan Wi-Fi dan membuat koneksi $\underline{T C P / I P}$ sederhana menggunakan perintah gaya Hayes lupa melakukan sitasi seperti sebelumnya [5].

2.3. Flowmeter

Sensor Flowmeter terdiri dari tubuh katup plastik, rotor air, dan sensor hall efek. Ketika air mengalir melalui, gulungan rotor-rotor.Kecepatan perubahan dengan tingkat yang berbeda aliran. Sesuai sensor hall efek output sinyal pulsa. Kelebihan sensor ini adalah hanya membutuhkan 1 sinyal (SIG) selain jalur 5V dc dan Ground. Prinsip kerja sensor ini adalah dengan memanfaatkan fenomena efek Hall [4].

\subsection{Generator}

Generator adalah sebuah perangkat elektronik yang dapat merubah tenaga mekanik menjadi tenaga listrik. Generator air memanfaatkan turbin yang berputar oleh aliran air yang terhubung dengan 
sebuah motor listrik. Motor listrik yang berputar akan menghasilkan arus listrik karena sebuah kumparan pada motor listrik akan memotong medan magnet pada motor yang menimbulkan arus listrik.

\subsection{Motor Servo}

Motor servo adalah sebuah motor dengan system closed feedback dimana posisi dari motor akan diinformasikan kembali ke rangkaian control yang ada di dalam motor servo [6].

\section{METODE PENELITIAN}

Metode penelitian dalam penghutungan penggunaan air ini ada beberapa tahapan yang dilakukan diantaran

1. Membuat blok diagram alat.

2. Perancangan pada perangkat keras (hardware)

3. Perancangan pada perangkat lunak (software)

4. Pengujian perangkat per elemen

5. Pengujian sistem.

Perancangan dalam suatu system dimaksudkan untuk mendapatkan rangkaian yang mudah dipahami oleh banyak orang dan sesuai dengan data sheet komponen yang dipakai atau system yang diinginkan. Pembuatan simulasi Analisa aliran air dengan adanya flowchat maka akan lebih mudah memahami prinsip kerja dari alat yang dibuat. Flowchar dari system dapat dilihat di gambar 1 .

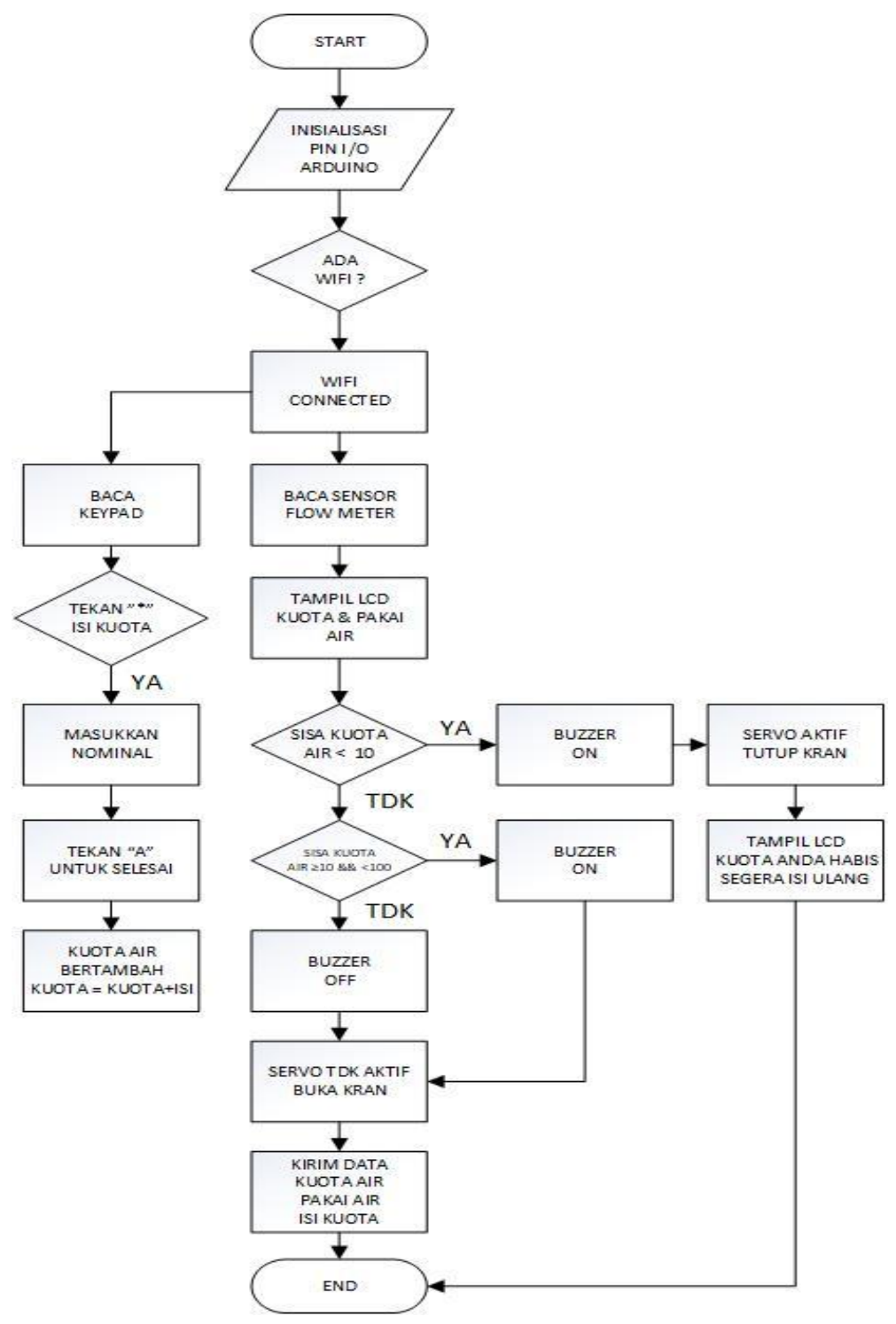

Gambar 1. Flowchart Sistem 
Prinsip kerjanya yaitu pertama menginisialisasi Pin I/O pada Arduino uno. Selanjutnya otomatis mencari WIFI setelah terhubung dengan WIFI, Pada Tampilan LCD terdapat kuota sisa debit air dan pemakaian debit air.

Keypad melakukan pengisian kode token dengan menekan tombol (*) selanjutnya diproses dengan memasukan kode token berupa rupiah beli kemudian tekan tombol (A). Dalam tampilan LCD nantinya akan ada penambahan debit sisa air yaitu Kuota ditambah dengan isi debit air. Harga per liter air saat ini memakai Rp.2000/1000L. Sensor flowmeter digunakan untuk mengukur volume air yang mengalir melewati sensor untuk diolah dan ditampilkan pada display LCD (Liquid Cristal Display) berapa volume air yang diukur dan otomatis mengurangi sisa debit air yang tersedia. Sisa debit air terus menerus berkurang sampai 100 liter maka buzzer akan berbunyi memberi peringatan dan apabila sisa debit air kurang dari 10 liter Servo mendapatkan sinyal untuk perintah menutup. Dalam tampilan LCD nantinya akan terdapat tulisan "KUOTA ADA HABIS SEGERA ISI ULANG". Arduino uno juga memproses hasil baca dari sensor flowmeter ini kepada modul wifi yang nantinya akan mengirimkan hasil informasi tersebut untuk di rekam secara berkala dan disimpan di web yang sudah terintegrasi oleh signal yang dikirimkan oleh reciver dari modul wifi yang nantinya hasil rekam informasi dari Arduino uno tersebut mampu diakses oleh server yang kemudian dapat dibaca oleh masing masing user, baik menggunakan media PC maupun dapat diakses pula menggunakan Android agar hasil pembacaan dapat diakses dimana dan kapan saja yang terkoneksi dengan internet.

\section{HASIL DAN PEMBAHASAN}

Pada penelitian ini untuk mengetahui kinerja dari alat Rancang Bangun Prototype Flowmeter Air Digital Prabayar Pada PDAM berbasis Online mengunakan Arduino Uno, maka dilakukan berbagai macam pengujian baik dalam sistem rangkaian, kinerja sensor, hingga pengujian alat secara individu maupun keseluruhan. Pengujian ini dilakukan untuk memastikan semua sistem sudah berjalan dan berfungsi dengan baik.

\subsection{Hasil Pengujian Flowmeter}

Pengujian Sensor flowmeter bertujuan untuk mengetahui berapa volume air yang mengalir melewati pipa. Pada pengujian kali ini membandingkan hasil pengukuran volume air secara manual dengan hasil yg terbaca pada tampilan layar Arduino uno. Setelah dilakukan pengujian maka akan terlihat perbandingan hasil ukurnya dibawah ini:

Tabel 1. Hasil Pengukuran Sensor Flowmeter

\begin{tabular}{ccccc}
\hline No & Volume Air Set ( L/m) & Volume Air Real (L/m) & Selisih Set-Real & Error \\
\hline 1 & 0,5 & 0,47 & 0,03 & $2 \%$ \\
2 & 1 & 1,03 & 0,03 & $3 \%$ \\
3 & 1,5 & 1,53 & 0,03 & $2 \%$ \\
4 & 2 & 2,09 & 0,09 & $4,5 \%$ \\
5 & 2,5 & 2,6 & 0,10 & $4 \%$ \\
& & & Rata-Rata Error & $3,1 \%$ \\
\hline
\end{tabular}

Dari tabel diatas untuk flowmeter ditemukan error sebesar 3,1\% masih dikatakan layak karena sesuai datasheet sensor Flowmeter dengan model YF-S201 tingkat akurasinya kurang lebih 10\% [7].

\subsection{Hasil Pengujian System Prabayar}

Pada pengujian system prabayar ini artinya system yang menggunakan kode token. Kode token disini adalah hasil konversi dari nilai rupiah menjadi volume air. Harga liter air saat ini memakai Rp.2000/1000 liter. Setelah dilakukan pengujian maka akan terlihat hasil nilai dibawah ini:

Tabel 2. Hasil Pengujian System Token Prabayar

\begin{tabular}{ccccccc}
\hline Kode Token & $\begin{array}{c}\text { Volume Air } \\
\text { Yang Didapat }\end{array}$ & $\begin{array}{c}\text { Kuota Air } \\
\text { Sebelum }\end{array}$ & $\begin{array}{c}\text { Kuota Air } \\
\text { Sesudah }\end{array}$ & Selisih & Error & Keterangan \\
\hline 2 & 1 & 10,00 & 11,00 & 0,0 & $0 \%$ & Berhasil \\
4 & 2 & 9,89 & 11,89 & 0,0 & $0 \%$ & Berhasil \\
6 & 3 & 9,90 & 12,90 & 0,0 & $0 \%$ & Berhasil \\
8 & 4 & 9,86 & 13,86 & 0,0 & $0 \%$ & Berhasil \\
10 & 5 & 9,97 & 14,97 & 0,0 & $0 \%$ & Berhasil \\
& & & & Rata-Rata Error & $0 \%$ & \\
\hline
\end{tabular}


Dari Tabel diatas untuk kode token tidak ada error dan dikatakan berhasil karena mendapatkan liter air sesuai dengan konvers nilai rupiah yang diinputkan.

\subsection{Hasil Pengujian Koneksi Web}

Selanjutnya dilakukan pengujian koneksi alat mengirim pada web. Untuk koneksi web perlu inputan, dimana inputan yang diambil dari meter air prabayar adalah input token untuk menambah kuota sisa air, total penggunaan liter air, dan kuota sisa air yang masih bisa digunakan. Pengiriman data pada alat dengan web, tentu ada waktu delay karena menggunakan internet. Hasil pengujian sistem alat dengan koneksi web dapat dilihat pada tabel 3 dibawah ini:

Tabel 3. Hasil Pengujian Delay Waktu Koneksi Alat dan Web

\begin{tabular}{cccc}
\hline No & Jam Alat & Jam Web & $\begin{array}{c}\text { Selisih } \\
\text { Alat-Web }\end{array}$ \\
\hline 1 & $20: 51: 00$ & $20: 51: 54$ & $00: 00: 24$ \\
2 & $20: 44: 00$ & $20: 44: 19$ & $00: 00: 19$ \\
3 & $20: 46: 00$ & $20: 47: 00$ & $00: 01: 00$ \\
4 & $20: 54: 00$ & $20: 54: 22$ & $00: 00: 22$ \\
5 & $20: 27: 10$ & $20: 28: 23$ & $00: 01: 13$ \\
& & Rata-Rata Delay & $00: 00: 40$ \\
\hline
\end{tabular}

Dari pengujian diatas didapatkan rata-rata waktu delay pengiriman data dari alat ke web sebesar 40 detik. Dibawah ini contoh tampilan pada web dan android pada field 2 yaitu monitoring kuota sisa air, sehingga memudahkan konsumen maupun petugas untuk memantau kapan saja dan dimana saja yang penting terdapat sinyal internet.

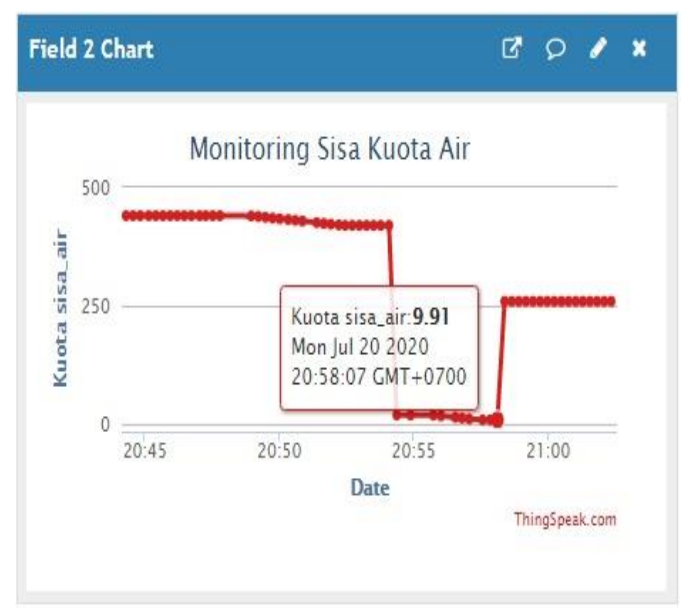

Gambar 2. Tampilan Pada Web

Pada Gambar diatas ini detail tampilan pada field 2 yaitu monitoring sisa kuota air. Data gambar 2 ini pengambilan pada tanggal 20 Juli 2020 dari jam 20.44 sampai 21.02 dengan keterangan gambar sebagai berikut:

1. Horizontal: Tanggal dan Jam pembacaan data.

2. Vertikal: Sisa kuota air yang masih bisa digunakan (liter). 


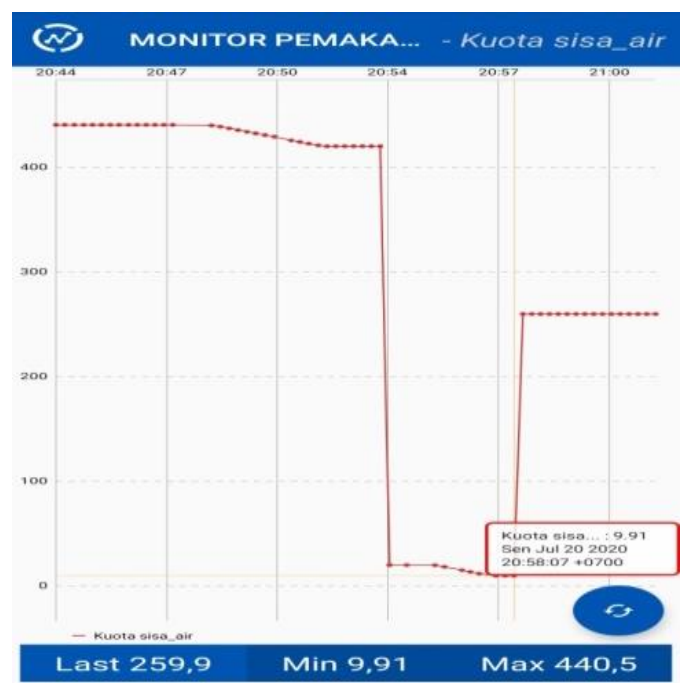

Gambar 3. Tampilan Pada Android

Gambar 3 ini detail tampilan pada grafik 2 yaitu monitoring sisa kuota air. Data gambar 3 ini pengambilan pada tanggal 20 Juli 2020 dari jam 20.44 sampai 21.02 dengan keterangan gambar sebagai berikut:

1. Horizontal: Tanggal dan Jam pembacaan data.

2. Vertikal: Sisa kuota air yang masih bisa digunakan (liter).

\section{KESIMPULAN}

Didasari berbagai tahapan yang telah dilakukan meliputi tahapan perancangan, perealisasian, pengujian, dan analisis maka secara keseluruhan dapat disimpulkan:

1. Rancangan Prototype Flowmeter Air Digital Prabayar pada PDAM berbasis online mengunakan Arduino Uno sudah sesuai yang diharapkan yaitu mampu mengukur volume air sesuai dengan volume air yang mengalir melalui sensor flow meter.

2. Sistem kerja alat secara keseluruhan sudah berhasil, diawali dengan input token tidak ada error, generator sebagai supply cadangan belum bisa bekerja maksimal karena tekanan air yang didapat tidak sampai 1,2 Megapascal. Alarm peringatan dan juga motor servo sudah bekerja sesuai perintah dari mikrokontrol.

3. ESP8266 V.1 menjadikan alat ini berbasis online, bisa memantau pemakaian air dan sisa kuota volume air secara real time dengan delay waktu antara alat dan web sebesar 40 detik. Sehingga sangat mudah dilihat dimana dan kapan saja yang terkoneksi dengan internet. Tetapi web ini masih terbatas karena hanya dapat melihat 1 konsumen saja.

\section{REFERENSI}

[1] Agustina, D. V, Analisa Kinerja sistem Distribusi Air Bersih PDAM Kecamatan Banyumanik di Perumnas Banyumanik, Universitas Diponegoro, Semarang, 2007.

[2] Rohman, Fathor, Prototype Alat Pengukuran Kecepatan Aliran Dan Debit Air (Flowmeter) Dengan Tampilan Digital, Universitas Gunadarma, Depok, 2009.

[3] Pradana, H. A, Rancang bangun Aplikasi Monitoring Penggunaan Air PDAM Berbasis Mikrokontrol Arduino Uno, STNIK Atma Luhur, Bangka Belitung, 2014.

[4] Rahman, F dan Kusworo Adi, Rancang Bangun Sistem Penghitung Penggunaan Air Prabayar menggunakan Mikrokontroler PIC16F877A, Universitas Diponegoro, Semarang, 2015.

[5] Sutanto, D, Pengendali Relay Via Internet Dengan Perintah Suara Google Assistant, Universitas Muhammadiyah Yogyakarta, Yogyakarta, 2018.

[6] Hidayat, L , Iswanto dan Helman Muhammad, Perancangan Robot Pemadam Api Divisi Senior Berkaki, Universitas Muhammadiyah Yogyakarta, Yogyakarta, 2011.

[7] Amperka, YFS201 Water Flow Sensor. [Online] Tersedia di :https:// https://files.amperka.ru/storemedia/products/water-flow-sensor/media/YF-S201.pdf (Diakses pada tanggal 20 April 2020). 


\section{BIOGRAFI PENULIS}

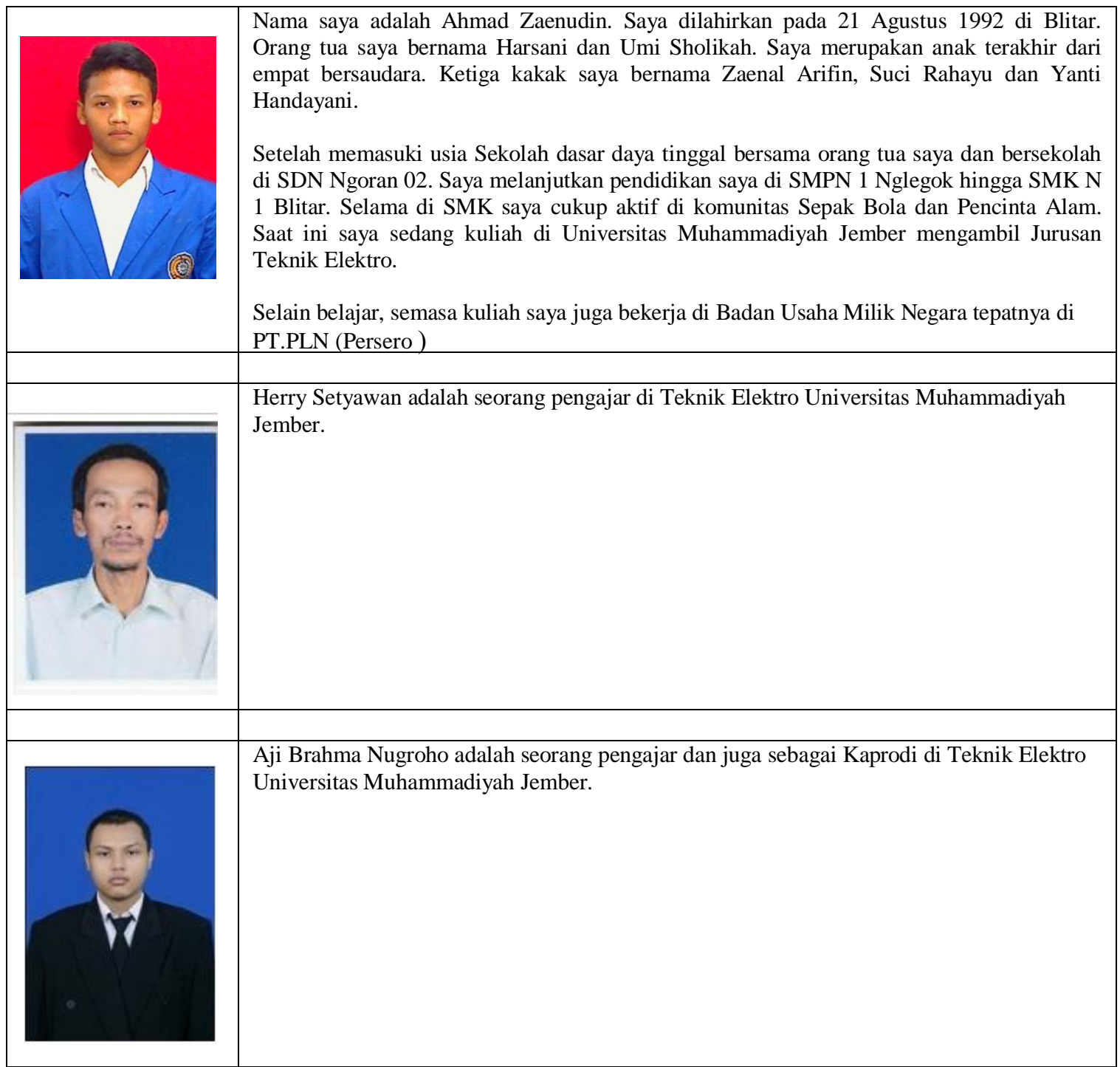

